ISSN 0103-9954

\title{
OS SOLOS DAS CAMPINARANAS NA AMAZÔNIA BRASILEIRA: ECOSSISTEMAS ARENÍCOLAS OLIGOTRÓFICOS ${ }^{1}$
}

\section{THE SOILS OF “CAMPINARANAS” IN BRAZILIAN AMAZON: OLIGOTHROPHIC SANDY ECOSYSTEMS}

\author{
Bruno Araujo Furtado de Mendonça ${ }^{2}$ Elpídio Inácio Fernandes Filho ${ }^{3}$ \\ Carlos Ernesto Gonçalves Reynaud Schaefer ${ }^{4}$ Felipe Nogueira Bello Simas ${ }^{3}$ \\ Mayara Daher de Paula ${ }^{5}$
}

\begin{abstract}
RESUMO
As Campinaranas são ecossistemas arenícolas de grande extensão na Amazônia brasileira, determinantes para os grandes sistemas de rios de águas pretas. Em vista da carência de estudos nestes ecossistemas, este trabalho teve como objetivos gerais estudar a distribuição das Campinaranas e suas relações com os solos predominantes e sua geologia na porção ocidental da Amazônia brasileira. Foram utilizados dados geográficos da vegetação, geologia e solos, além dos dados analíticos dos perfis de solos coletados pelo Projeto RADAMBRASIL, atualizados e sistematizados pelo IBGE, somados a perfis de referência coletados no Parque Nacional do Viruá, Roraima. De modo geral, os solos das Campinaranas são predominantemente arenosos, desenvolvidos sobre materiais de origem de natureza arenoquartzosa. Do cruzamento dos dados geológicos com áreas dominadas por Campinaranas, tem-se um predomínio das formações sedimentares recentes (Quaternário), constituídas principalmente de materiais arenosos. A partir

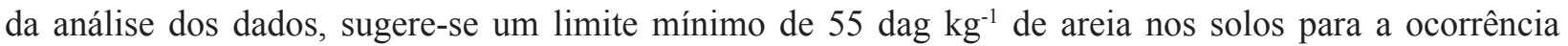
das Campinaranas. Os solos mais argilosos são reportados apenas para as áreas ecotonais Florestas - Campinaranas, marginais aos corpos arenosos. Verifica-se predomínio absoluto dos Espodossolos e Neossolos Quartzarênicos nas Campinaranas. Mesmo em diferentes formações geológicas e com processos pedogenéticos distintos, estes solos possuem características morfológicas, químicas e físicas muito semelhantes. Apesar da diversidade pedológica das áreas ecotonais, os solos encontrados guardam semelhanças com os solos das Campinaranas.
\end{abstract}

Palavras-chave: Espodossolos; Neossolos Quartzarênicos; Amazônia brasileira; Ecossistemas arenícolas.

\begin{abstract}
"Campinaranas" are sandy ecosystems of great extension in the Brazilian Amazon, and are determinant for the great systems of rivers with black waters. Due to the lack of studies on this ecosystem, the objective of the present work was to study the distribution of "Campinaranas" and their relationship with the predominant soils and geology in the western portion of the Brazilian Amazon. We used geographic data of vegetation, geology and soils, and analytical data of the soil profiles collected by the RADAMBRASIL project, updated and systematized by IBGE, and data from reference profiles collected in the National Park of Viruá,

1 Parte da Tese de Doutorado do primeiro autor, apresentada à Universidade Federal de Viçosa.

2 Engenheiro Florestal, Dr., Professor Adjunto-A do Departamento de Silvicultura, Instituto de Florestas, Universidade Federal Rural do Rio de Janeiro, 23897-005, Seropédica (RJ), BRASIL. Bolsista do CNPq. brunoafmendonca@gmail.com

3 Engenheiro Agrônomo, Dr., Professor Associado do Departamento de Solos, Universidade Federal de Viçosa, CEP 36570-900, Viçosa (MG), Brasil. elpidio@ufv.br / fnbsimas@gmail.com

4 Engenheiro Agrônomo. PhD em Solos, Professor Associado do Departamento de Solos, Universidade Federal de Viçosa, CEP 36570-900, Viçosa (MG), Brasil. carlos.schaefer@ufv.br

5 Geógrafa, Mestranda em Solos e Nutrição de Plantas. Departamento de Solos, Universidade Federal de Viçosa, CEP 36570-900, Viçosa (MG), Brasil. Bolsista de Iniciação Científica PIC/CAIXA/UFV-2010/UFV. mayara_daher@hotmail.com
\end{abstract}

Recebido para publicação em 14/06/2011 e aceito em 07/01/2014

Ci. Fl., v. 25, n. 4, out.-dez., 2015 
Roraima. In general, the soils of "Campinaranas" are predominantly sandy, developed on parent materials rich in quartz. The overlaying of geological data with areas dominated by "Campinaranas", reveals the prevalence of recent sedimentary formations (Quaternary), constituted mainly of sandy materials. Based on the studied dataset, we suggest a minimum limit of $55 \mathrm{dag} \mathrm{kg}^{-1}$ of sand in the soils for the occurrence of "Campinaranas". Soils with higher clay content are present only in Forest-Campinaranas transitions, adjacent to the sandy deposits. It is verified the absolute prevalence of Spodosols and Psamments in "Campinaranas". Even in different geological formations and under distinct pedogenetic processes, these soils possess similar morphological, chemical and physical properties. In spite of the pedological diversity found in the transitional areas, the soils keep similarities with the soils of "Campinaranas".

Keywords: Spodosols; Psamments; Brazilian Amazon; Sandy Ecosystems.

\section{INTRODUÇÃO}

As Campinaranas, também conhecidas como Campinas ou Caatingas Amazônicas (ANDERSON, 1981), são ecossistemas que ocorrem nas áreas de clima úmido e solos arenosos, predominantemente hidromórficos da Amazônia. Caracterizam-se por uma paisagem marcante, de exceção à Floresta Tropical envolvente, pois apresenta contrastes em termos bióticos e abióticos. Suas fitofisionomias são fortemente influenciadas pelos ciclos sazonais e pelas variações nos níveis do lençol freático, em gradações fitofisionômicas associadas a diferentes níveis de hidromorfismo. Conforme aumenta o encharcamento dos solos, as Campinaranas Florestadas são substituídas por formações de Campinarana Arborizada, passando pelas Gramíneo-Lenhosas até puramente Herbáceas, com feição de campos brejosos.

A presença de solos arenosos, com baixa fertilidade, hidromórficos e não indicados para a agricultura justificou o uso de muitas áreas para extração de areia destinada à construção civil (ANDERSON, 1981), o que caracteriza uma forte ameaça a estes ecossistemas. Além disso, as condições edáficas particulares e a vegetação altamente adaptada, formando ilhas de vegetação na Amazônia, com a presença de um grande número de espécies endêmicas e com nichos específicos (PRANCE, 1996), são indicadores da vocação destas áreas para conservação e recreação, sendo indicadas principalmente como Reservas e Parques.

A literatura sobre as Campinaranas Amazônicas é escassa, com muitas discussões e controvérsias quanto à origem desta vegetação (DUCKE e BLACK, 1954; ANDERSON etal., 1975; ANDERSON, 1978; PRANCE e SCHUBART, 1978; ANDERSON, 1981; FERREIRA, 1997). Campinaranas estão distribuídas desde o alto
Rio Negro, além do norte-noroeste do Brasil até a região de Vaupés e Caquetá na Colômbia, ao sul da Venezuela, em grandes áreas no alto Tapajós, perto da margem direita do Rio Madeira e, ainda, em pequenas manchas, como enclaves de vegetação, no sudoeste da Amazônia (IBGE, 1992; DUIVENVOORDEN, 1996; OLIVEIRA e DALY, 2001; ALONSO, 2002; SILVEIRA, 2003; POLETO e ALEIXO, 2005). No território brasileiro, sua maior concentração está na região centro-sul do Estado de Roraima e, especialmente, no noroeste do Amazonas, na bacia do Rio Negro. Nesta região, a relação entre a fitomassa e a taxa anual de precipitação pluvial diminui no sentido Leste-Oeste, pois estão relacionadas diretamente com os processos de podzolização e arenização dos solos que, por sua vez, são associados à elevada lixiviação e consequente empobrecimento químico destes solos (SCHAEFER et al., 2007).

Os solos predominantes são desenvolvidos de material de origem retrabalhado proveniente do Pré-Cambriano (gnaisses e granitos), recobertos por sedimentos arenoargilosos de Idade Pliopleistocênica. Destes materiais, desenvolveram-se mantos arenosos profundos, formados por pedogênese in situ como demonstram os estudos no Estado do Amazonas (BRAVARD e RIGHI, 1990; ANDRADE et al., 1997; LUCAS et al., 1984). Compreende um extenso domínio de Espodossolos e Neossolos Quartzarênicos, muitas vezes hidromórficos, em um relevo plano a suave ondulado. São solos arenosos a francoarenosos, de natureza quartzosa, com muita areia fina, profundos e, algumas vezes, ricos em material orgânico em subsuperfície; são quimicamente muito pobres, distróficos e ácidos (BRASIL, 1975a).

Mesmo com ampla distribuição espacial, as dificuldades de acesso, a grande profundidade dos horizontes arenosos, a presença frequente 
do lençol freático elevado (hidromorfismo) e os horizontes cimentados são aspectos que contribuem para a falta de estudos da gênese destes solos, bem como de suas funções ecológicas (DUBROEUCQ e BLANCANEAUX, 1987; DUBROEUQ e VOLKOFF, 1998). Além disso, as condições climáticas atuais de elevada precipitação pluvial, com chuvas torrenciais, compreendidas entre as isoietas de 1.800 a $3.000 \mathrm{~mm}$ anuais (INMET, 2008), dificultam ainda mais a logística destes estudos. No entanto, na década de 70, o Governo Federal, com o Programa de Integração Nacional, realizou um dos principais levantamentos e mapeamento pedológico para esta região, considerado como referência para os dias atuais, o Projeto RADAMBRASIL (BRASIL，1975a; 1975b; 1976; 1977a; 1977b; 1978).

O presente trabalho teve como objetivo geral estudar os solos das Campinaranas e as relações com o clima e geologia na porção ocidental da Amazônia brasileira, assim como compor um banco de dados de perfis de solos coletados nestes ambientes e avaliar as características químicas e físicas dos principais solos.

\section{MATERIAL E MÉTODOS}

\section{Área de estudo}

A área estudada compreende toda porção da Amazônia brasileira com ocorrência da vegetação de Campinaranas e áreas ecotonais (Figura 1), mapeadas pelo Projeto RADAMBRASIL (BRASIL, 1975a; 1975b; 1976; 1977a; 1977b; 1978) e IBGE (2000).

De modo geral, a região possui condição climática tipicamente equatorial, com chuvas fortes e torrenciais, delimitada por um período seco de pequena duração. A precipitação pluvial é alta (1.800 a $3.000 \mathrm{~mm}$ anuais) e a temperatura média anual varia de 24 a $28^{\circ} \mathrm{C}$, com máxima de $34^{\circ} \mathrm{C}$ e mínima de $18^{\circ} \mathrm{C}$ (INMET, 2008).

O relevo predominante é plano a suave ondulado, com altitude média de 80 metros acima do nível do mar (IBGE, 2000; JARVIS et al., 2006). A área em estudo está localizada no Pediplano Rio Branco - Rio Negro, recoberta de sedimentos arenosos, classificados nos estudos geológicos como Formação Içá, referida aos mantos arenosos

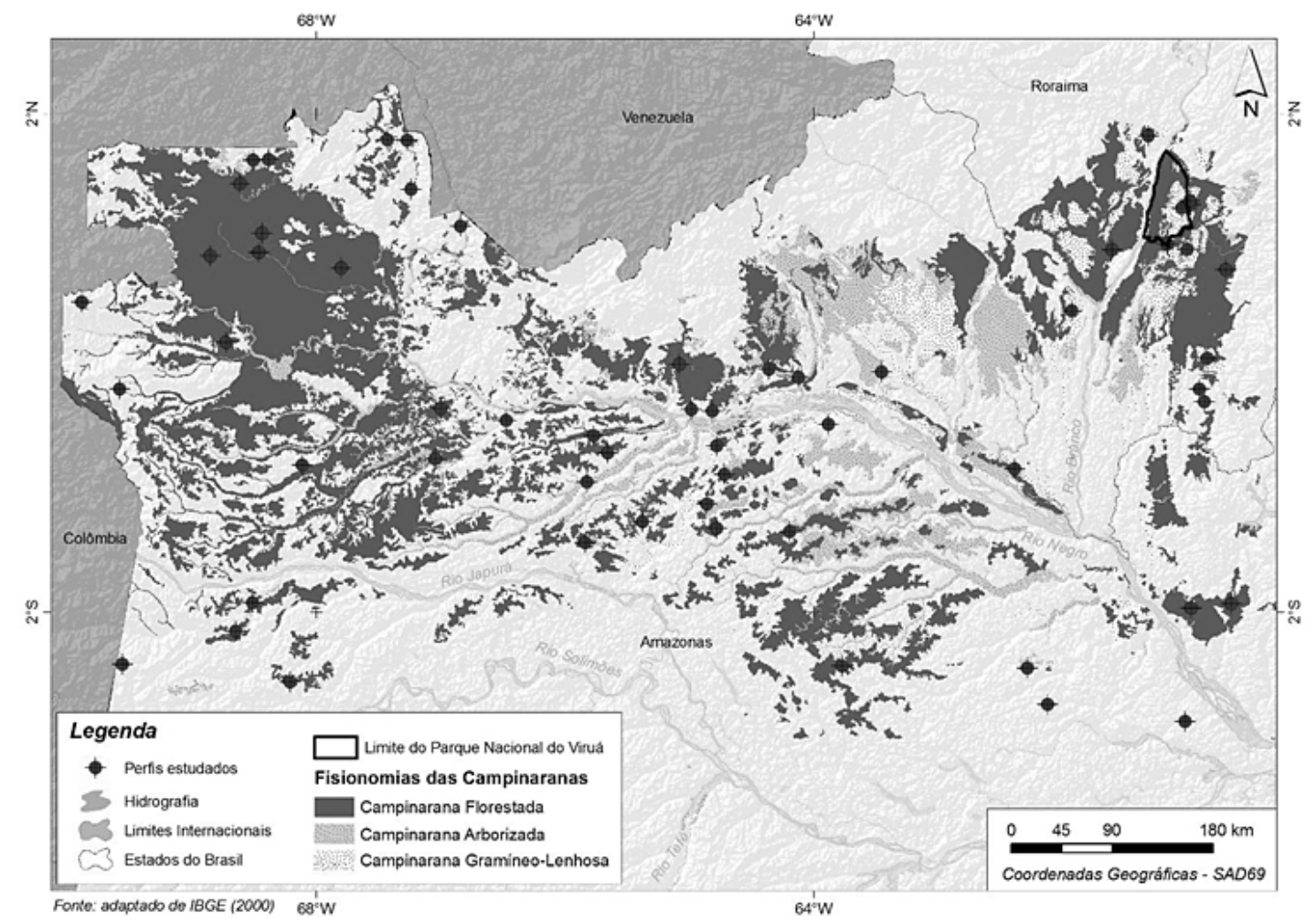

FIGURA 1: Localização dos principais perfis de solos estudados com a distribuição predominante das Campinaranas na Amazônia Ocidental Brasileira.

FIGURE 1: Location of the main profiles of studied soils with the predominant distribution of Campinaranas in the Western Brazilian Amazon. 
com lentes de matéria orgânica (BRASIL, 1975a; 1976; 1977b; 1978).

\section{Fitofisionomias das Campinaranas Amazônicas}

De acordo com a classificação de Veloso et al. (1991), o sistema fitofisionômico-ecológico das Campinaranas é divido em três subgrupos de formação: as Campinaranas Florestadas, Arborizadas e Gramíneo-Lenhosas. Na Campinarana Florestada, o nível do lençol freático, normalmente, não aflora em superfície, o que permite um porte maior da vegetação constituída por uma fisionomia florestal com árvores relativamente finas (Figura 2 - A), com até $15 \mathrm{~m}$ de altura. As árvores possuem caules eretos, pouco ou nada tortuosos (Figura 2A) e formam um dossel quase contínuo, às vezes mais aberto. Nas Campinaranas Arborizadas, o porte da vegetação é menor e mais raquítico (Figura 2B), mas muitas vezes com espécies semelhantes às Campinaranas Florestadas.

Nas Campinaranas Gramíneo-Lenhosas, o período prolongado de inundação sazonal dos solos aumenta a dificuldade para o estabelecimento de árvores de maior porte (Figura 2D). Nestes ambientes ocorrem áreas de maior exposição aos ventos e que nas fases mais secas de períodos glaciais promoveram a ativação dos campos de dunas. Destacam-se na região do baixo Rio Branco e parte do Rio Negro, áreas com dunas inativas e parcialmente vegetadas (Figura 2C). Constituem dunas parabólicas e longitudinais, alongadas paralelamente segundo a direção do vento predominante, de NE para SW. Nas áreas dos lagos interdunas predominam os buritizais (Mauritia sp.). Nas fitofisionomias mais arbóreas (Figura 2 A e B) predominam os Espodossolos (Figura $2 \mathrm{a}$ e b) e nas Campinaranas Gramíneo-Lenhosas (Figura $2 \mathrm{C}$ e D) os Neossolos Quartzarênicos (Figura 2d). Ocorrem ainda Espodossolos (Figura 2c) como inclusão nas áreas próximas aos arbustos em dunas inativas (Figura 2C).

\section{Banco de Dados}

\section{Base de dados geográficos}

O presente trabalho teve como principal base digital cartográfica os dados obtidos na atualização e sistematização das informações dos recursos naturais da Amazônia, desenvolvidos pelo IBGE (2000), o qual inclui os mapeamentos realizados pelo Projeto RADAMBRASIL na década de 70 de vegetação, geologia e solos. Além disso, foram utilizados dados climáticos da classificação Köppen (PEEL et al., 2007). Assim, os dados de vegetação para as fitofisionomias das Campinaranas (Figura 1) foram cruzados com as bases de clima, geologia e solos da Amazônia Ocidental e que incluíram os estados do Amazonas e Roraima. Foram utilizadas técnicas básicas de geoprocessamento para a interseção das unidades de mapeamento, através do software ArcGIS 9.3.

Para as unidades de mapeamento dos solos foi considerado apenas o primeiro componente de cada associação na legenda, por exemplo, para uma classe de Latossolo Amarelo associada a um Argissolo Amarelo, foi adotado o Latossolo Amarelo como unidade de mapeamento, pois esta demonstra a classe mais representativa. No total, os mapas originais de solos de toda a Amazônia Ocidental contêm 14.623 polígonos organizados em 381 unidades de mapeamento, compostas pela classe principal e as respectivas associações e/ou inclusões. No mapeamento geológico são 16.533 polígonos para representar 117 unidades geológicas no total.

Assim, a partir da integração dos dados foi avaliada a distribuição geral das Campinaranas em toda a Amazônia Ocidental, sobre os diferentes substratos geológicos e pedológicos.

\section{Base de dados analíticos dos perfis de solo}

O banco de dados georreferenciados dos perfis de solos foi elaborado a partir do conjunto de perfis de solos coletados pelo Projeto RADAMBRASIL (BRASIL, 1975a; 1975b; 1976; 1977a; 1977b; 1978) nas áreas sob domínio da região fitoecológica das Campinaranas e em Áreas de Tensão Ecológica, no contato Campinarana/Floresta Aberta ou Densa, bem como de perfis de referência, coletados no Parque Nacional do Viruá e entorno, no estado de Roraima, contendo dados das análises químicas e físicas dos solos. Foram selecionados 67 perfis de solos, 32 sob domínio da região fitoecológica das Campinaranas e 35 em Áreas de Tensão Ecológica, no contato Campinarana/Floresta Aberta ou Densa.

Para a organização dos perfis em fitofisionomias foram utilizadas as descrições de campo, obtidas nos relatórios do Projeto RADAMBRASIL, assim como as coordenadas geográficas cruzadas com mapa de vegetação e 

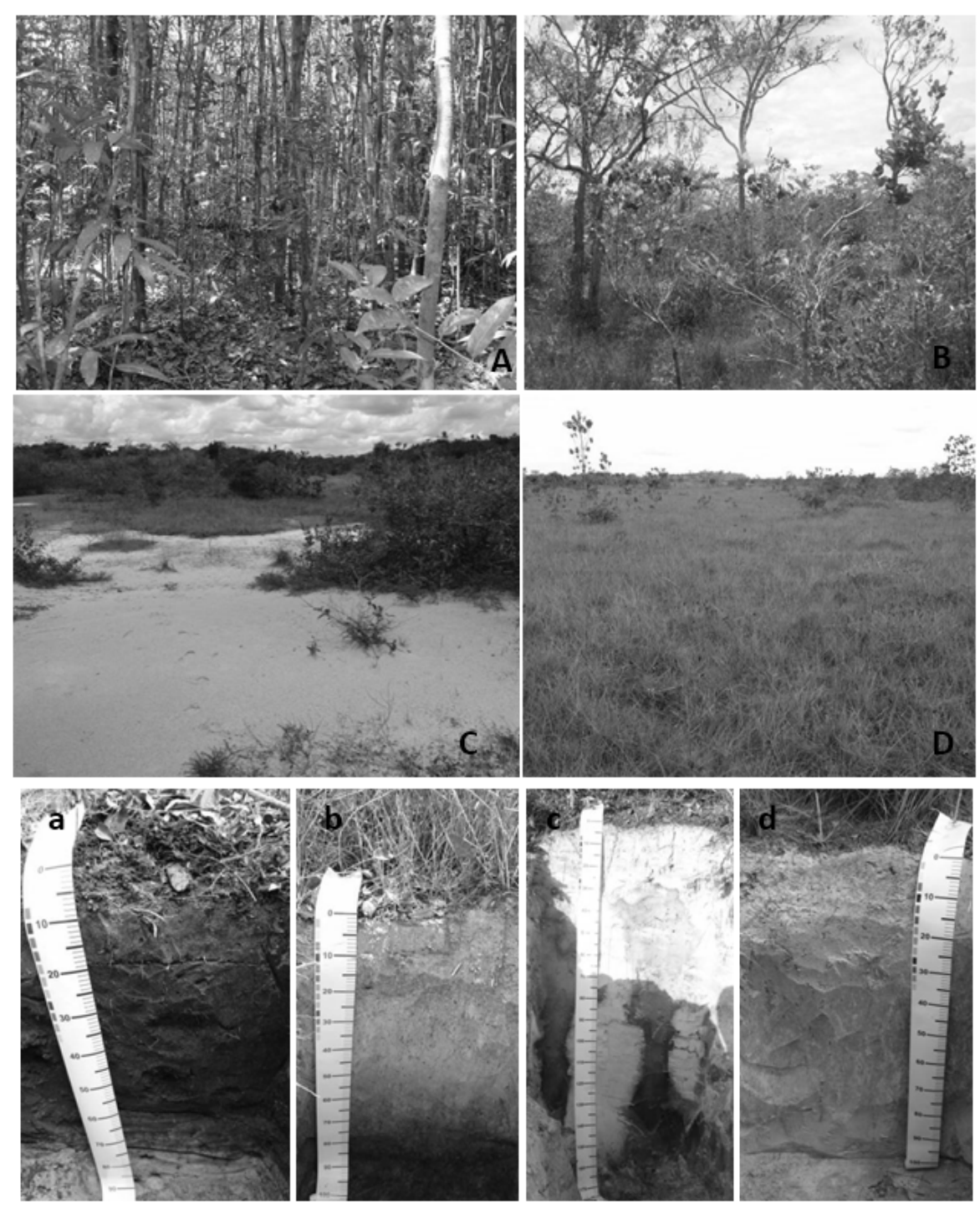

FIGURA 2: Fitofisionomias típicas das Campinaranas no Parna Viruá (Roraima) e respectivos perfis representativos dos solos: (A e a) Campinarana Florestada e perfil de Espodossolo Humilúvico Hidromórfico arênico; ( $\mathrm{B}$ e b) Campinarana Arbóreo-Arbustiva e perfil de Espodossolo Humilúvico Hidromórfico arênico; (C e c) Campinarana Gramíneo-Lenhosa em duna inativa e perfil de Espodossolo Humilúvico Órtico espessarênico; (D e d) Campinarana GramíneoLenhosa e perfil de Neossolo Quartzarênico Hidromórfico típico.

FIGURE 2: Vegetation types of Campinaranas at Parna Viruá (Roraima) and respective representative soils profiles: (A e a) "Campinarana Florestada" and Espodossolo Humilúvico Hidromórfico arênico; (B e b) "Campinarana Arbóreo-Arbustiva" and Espodossolo Humilúvico Hidromórfico arênico; (C e c) "Campinarana Gramíneo-Lenhosa" in inactive dune and Espodossolo Humilúvico Órtico espessarênico; (D e d) "Campianarana Gramíneo-Lenhosa” and Neossolo Quartzarênico Hidromórfico típico.

solos, quando não havia as descrições no relatório. Apesar da diferenciação entre as fitofisionomias das Campinaranas seguir a classificação de Veloso et al. (1991), as descrições de campo dos perfis de solos coletados pelo projeto RADAMBRASIL não constam tais subdivisões. Assim, para a identificação das subdivisões das Campinaranas (Florestada, Arborizada e Gramíneo-Lenhosa) foi realizado o cruzamento das coordenadas geográficas dos perfis com o mapa de vegetação, os quais possuem maior detalhamento das regiões fitoecológicas. Quando o perfil ocorreu em área de contato Campinarana/ 
Floresta no mapa de vegetação, e consta na descrição do perfil como cobertura vegetal de Campinarana, considerou-se a tipologia Campinarana Florestada, em razão das semelhanças mais evidentes comparadas à Arborizada e Gramíneo-Lenhosa.

Os perfis de solos foram organizados em classes, no primeiro nível categórico, para cada fitofisionomia. Para a discussão dos dados, os solos foram agrupados em horizontes superficiais e subsuperficiais e calculadas as médias ponderadas pelas espessuras e o desvio padrão das seguintes análises químicas e físicas: $\mathrm{pH} \mathrm{H}_{2} \mathrm{O}$, fósforo assimilável (P), soma de bases (SB), capacidade de troca catiônica a $\mathrm{pH}$ 7,0 (T), saturação por bases (V), saturação por Alumínio (m), matéria orgânica (MO), areia grossa, areia fina, silte e argila. No caso dos Espodossolos e Neossolos Quartzarênicos, os horizontes foram agrupados em três camadas principais, a saber: superficial a qual inclui apenas os horizontes A1; eluvial inclui os horizontes A2 (os horizontes A2 são camadas de depleção, lixiviados, também chamadas atualmente de horizontes E, eluviais; na Amazônia, estes horizontes podem variar de 20 a $200 \mathrm{~cm}$ (SOMBROEK, 1966)) e E, com todas as subdivisões presentes $(\mathrm{E} 1, \mathrm{E} 2, \mathrm{E} 3, \ldots)$; subsuperficial inclui horizontes B diagnósticos (Bs, Bhs, Bh) ou apenas $\mathrm{C} 1$. Tal separação considerou a diferenciação genética dos horizontes eluviais (ou deplecionais) extremamente importante para a análise dos Espodossolos e Neossolos Quartzarênicos. Entretanto, para os demais solos, como esta camada (eluvial) é praticamente ausente ou de pequena espessura, foram agrupados em apenas duas camadas: superficial e subsuperficial.

\section{RESULTADOS E DISCUSSÕES}

\section{Aspectos climáticos}

Dentre as tipologias da classificação de Köppen, de acordo com Peel et al. (2007), ocorrem os seguintes subtipos tropicais (A), com a temperatura média do mês mais frio do ano $\geq 18^{\circ} \mathrm{C}$ : Af (clima tropical úmido ou clima equatorial, com precipitação pluvial do mês mais seco $\geq 60 \mathrm{~mm}$ ), Am (clima de monção, exceto Af e com precipitação pluvial do mês mais seco $\geq 100 \mathrm{~mm}$ - [precipitação média anual/25]) e Aw (clima tropical com estação seca de inverno, exceto Af e com precipitação pluvial do mês mais seco $<100 \mathrm{~mm}-$ [precipitação média anual/25]).

A partir do cruzamento das áreas mapeadas com Campinarana (IBGE, 2000) com os dados georreferenciados da classificação de Köppen (PEEL et al., 2007), 76\% estão sob o tipo Af, 10\% em Am e 14\% para Aw; o que está relacionado com as características dessa vegetação, algumas vezes denominadas de vegetação de influência pluvial (BRASIL, 1977b). De acordo com Schaefer et al. (2007), a região da bacia do Rio Negro possui estreitas relações entre a precipitação pluvial elevada e o carbono no solo e na biomassa da vegetação (tipicamente de Campinaranas). Tais relações são associadas ao elevado intemperismo químico, arenização dos solos, superfícies rebaixadas, baixa produção de carbono na biomassa vegetal e, consequentemente, a iluviação do $\mathrm{C}$ dos horizontes superficiais para as camadas subsuperficiais, os horizontes espódicos, o que reflete na exportação do $\mathrm{C}$ no ambiente natural. Isso é ilustrado pela ampla distribuição dos rios de águas pretas que drenam a bacia do Rio Negro. Segundo Sioli (1962), nestas condições de predomínio de solos arenosos, os rios são ricos em ácidos húmicos e material turfoso inerte em suspensão.

\section{Geologia das Campinaranas: distribuição e caracterização}

A partir do cruzamento dos dados geológicos com as áreas dominadas pelas fitofisionomias das Campinaranas da Amazônia Ocidental (IBGE, 2000), tem-se um predomínio das formações sedimentares recentes (Quaternário), as quais são constituídas principalmente de materiais arenosos. Tais materiais arenosos são fortemente associados a esta vegetação. Destacam-se a Formação Içá com $63,7 \%$ de toda área estudada, os Aluviões Holocênicos com 10\% e a Cobertura DetritoLaterítica Pleistocênica com 7\% (Tabela 1). A unidade descrita como "Outras", com 4,8\% da área, corresponde a mais de 30 unidades geológicas, constituídas por pequenos polígonos localizados nas bordas das unidades principais. Estes polígonos são muitas vezes problemas cartográficos de escala e delineamentos mais generalizados, pois as interpretações e os mapeamentos foram realizados por diferentes profissionais e com técnicas distintas, a saber: os geólogos e os botânicos.

A Formação Içá é constituída de sedimentos arenosos inconsolidados a semiconsolidados sem exibir estratificação horizontal evidente, aflorantes na bacia do Rio Branco e Rio Negro e, em virtude da semelhança com a Formação Solimões, nas 
TABELA 1: Unidades geológicas presentes nas Campinaranas mapeadas pelo Projeto RADAMBRASIL (BRASIL, 1975a; 1975b; 1976; 1977a; 1977b; 1978) e IBGE (2000).

TABLE 1: Geological units in Campinaranas mapped by the RADAMBRASIL Project (BRASIL, 1975a; 1975b; 1976; 1977a; 1977b; 1978) and IBGE (2000).

\begin{tabular}{lcc}
\hline \multicolumn{1}{c}{ Unidades Geológicas } & Área $\left(\mathrm{km}^{2}\right)$ & Área em \% \\
\hline Formação Içá & 120361,6 & 63,7 \\
Aluviões Holocênicos & 18951,0 & 10,0 \\
Cobertura Detrito-Laterítica Pleistocênica & 13279,3 & 7,0 \\
Terraços Holocênicos & 7147,7 & 3,8 \\
Complexo Cauaburi & 3210,5 & 1,7 \\
Suíte Intrusiva Curicuriari & 2245,4 & 1,2 \\
Grupo Trombetas & 1920,4 & 1,0 \\
Coberturas Eólicas Holocênicas & 1818,0 & 1,0 \\
Coluviões Holocênicos & 1766,2 & 0,9 \\
\hline Outras & 9126,3 & 4,8 \\
\hline
\end{tabular}

bacias do Acre e do Alto Amazonas (BRASIL, 1975a; CPRM, 2000). A presença generalizada das Campinaranas sobre esta unidade restringe-se principalmente à bacia do Rio Negro, provavelmente associada a condições climáticas mais úmidas e favoráveis aos processos de podzolização e arenização dos solos (SCHAEFER et al., 2007). Maia et al. (1977) citado por CPRM (2000), em estudos na região do Alto Rio Solimões, destacaram que a Formação Solimões é recoberta por um pacote sedimentar constituído predominantemente por arenitos friáveis amarelo-avermelhados de granulometria fina a conglomerática, denominando esse conjunto de Formação Içá e interpretaram-no como tipicamente continental. Esses sedimentos, de idade pleistocênica, foram depositados em ambiente continental, fluvial, associado às planícies de inundação e/ou meandros abandonados. Atualmente, possui áreas recobertas por depósitos aluvionares e eólicos recentes oriundos, principalmente, do retrabalhamento de suas próprias camadas (CPRM, 2000); essas unidades correspondem aos aluviões e terraços Holocênicos e as coberturas eólicas Holocênicas, respectivamente.

Os Aluviões Holocênicos são depósitos de grande extensão lateral, recentes, constituídos predominantemente por sedimentos arenosos e cascalhentos, além de sedimentos siltosos e argilosos e conglomerados; encontrados em praticamente todos os rios da região (BRASIL, 1975a, 1975b, 1976, 1977a, 1977b, 1978; CPRM, 2000). Com constituição semelhante, típica dos depósitos fluviais, os Terraços Holocênicos são depósitos encontrados sobre terraços, que foram palco de antigas planícies de inundação. Em ambas as condições predominam as Campinaranas Florestadas, também denominadas de Florestas de Igapó, nas quais as inundações, por ocasião do transbordamento dos rios, apresentam-se com fraca deposição de sedimentos minerais. Spruce (1908) citado por Veloso et al. (1991) foi o pioneiro no uso do termo "Caatinga-gapó", o qual significa uma vegetação lenhosa dos pântanos (VELOSO et al., 1991), em referência ao termo igapó.

Sobre as Coberturas Eólicas Holocênicas, há diversas referências relatadas há muito tempo na literatura nas bacias dos Rios Branco e Tacutu (SCHAFER e DALRYMPLE, 1995). São depósitos eólicos constituídos por areia bimodal, bem arredondada, grãos foscos, de granulação fina a média e estratificações cruzadas de médio a grande porte e superfícies de deflação (IBGE, 2000). Santos e Nelson (1995) relatam a ocorrência dos campos de dunas fósseis nas áreas de maior exposição aos ventos, que, nas fases mais secas de períodos glaciais, promoveram a ativação das dunas, atualmente estacionadas e parcialmente vegetadas.

Quanto às Coberturas Detrito-Lateríticas Pleistocênicas, estas são constituídas por sedimentos argiloarenosos amarelados, cauliníticos, alóctones e autóctones, parcial a totalmente pedogeneizados (Latossolos argiloarenosos), gerados por processos alúvio-coluvionar (IBGE, 2000). Tais formações parecem correlacionar-se com as áreas ecotonais 
das Campinaranas, citadas por alguns autores como possíveis precursoras das areias quartzosas hidromórficas (BRAVARD e RIGHI, 1990; ANDRADE et al., 1997; LUCAS et al., 1984; MAFRA et al., 2002), em razão dos processos pedogenéticos clássicos dos solos alagados, a ferrólise e a acidólise (BRINKMAN, 1970; ANDRADE, 1990).

Com exceção do Complexo Cauaburi $(1,7 \%)$ e a Suíte Intrusiva Curicuriari (1,2\%), constituídos respectivamente por rochas metamórficas e plutônicas, as principais unidades geológicas encontradas sob as Campinaranas são rochas sedimentares clásticas. O Complexo Cauaburi e a Suíte Intrusiva Curicuriari são unidades geológicas que se limitam com as unidades sedimentares predominantes. Portanto, a inclusão dessas unidades, possivelmente, está relacionada às generalizações do mapeamento cartográfico, as quais incluem apenas áreas de borda. Estas unidades podem ocorrer na forma de inselbergs florestados, caracterizados por relevos residuais de destaque na paisagem regional extremamente aplainada, sob o domínio das Campinaranas. Em menor proporção, mas associados a essas elevações, no sopé das montanhas, ocorrem os coluviões Holocênicos constituídos de partículas angulares a ligeiramente arredondadas, comumente de cor vermelha, contendo fragmentos de rocha e sedimentos finos a grosseiros (IBGE, 2000).

O Grupo Trombetas pertence ao Siluriano Inferior (Paleozoico) e é constituído por intercalações de arenitos, siltitos e folhelhos, havendo predominância de arenitos na base e os folhelhos no topo da seção; distribuindo-se desde as proximidades de Manaus até próximo a Ilha de Marajó em um alinhamento paralelo ao Rio Amazonas (IBGE, 2000). As áreas dominadas pelas Campinaranas Florestadas (ou Florestas de Igapó) pertencentes a este Grupo ocorrem a alguns quilômetros de Manaus, nas adjacências da região conhecida entre os maiores arquipélagos fluviais do mundo, as Anavilhanas (OLIVEIRA e DALY, 2001).

\section{Distribuição dos solos: integração Solos $\mathrm{X}$ Campinaranas}

De acordo com o mapeamento dos solos (IBGE, 2000) presentes nas Campinaranas, destacam-se os Espodossolos com mais de 55\% de ocorrência, distribuídos por quase toda a área estudada (Tabela 2). Os Neossolos Quartzarênicos, com quase $10 \%$, ocupam principalmente a região da margem esquerda do Rio Negro, ao norte do Equador, próximo dos sopés de conjuntos serranos do Complexo Guianense, mais ao norte. Os solos arenosos são determinantes para a ocorrência das Campinaranas, no entanto, esta vegetação é associada principalmente às condições climáticas, sendo também denominadas de vegetação de influência pluvial (BRASIL, 1977b). Assim, a influência serrana do Complexo Guianense contribui para o aumento das precipitações pluviais orográficas e, consequentemente, favorecimento dos processos pedogenéticos de podzolização e arenização dos solos.

Os solos mais argilosos, principalmente os Argissolos, são reportados para as áreas ecotonais Florestas-Campinaranas, marginais às areias quartzosas hidromórficas, associados aos inselbergs, colinas, encostas dissecadas, rampas e superfícies pediplanadas. Os Latossolos, Gleissolos e Plintossolos não ocorrem em áreas de Campinaranas, assim, sua inclusão no cruzamento dos dados, com mais de $25 \%$, se deve provavelmente aos erros cartográficos de escala (Tabela 2).

\section{Características analíticas dos principais solos das Campinaranas e áreas ecotonais}

A partir do banco de dados elaborado, destacam-se os Espodossolos e os Neossolos, com ocorrência em todas as fisionomias estudadas. Nas áreas de Campinaranas e de contato Campinaranas/ Florestas, ocorrem 24 Espodossolos e 14 Neossolos (Tabela 3), o que corresponde a 57\% perfis de solos estudados. Estes solos são predominantemente arenosos, provenientes de materiais de origem de natureza arenoquartzosa.

Nas Campinaranas também predominam os Espodossolos e os Neossolos, no entanto foram descritas outras classes de solos para esta vegetação (Tabela 3). Para os outros solos, possivelmente, a vegetação descrita confunde-se com as Formações Pioneiras ou correspondem a possíveis erros de interpretação dos pedólogos em áreas ecotonais ou ainda, são inclusões de perfis de solo em unidades de mapeamento mais extensas das Campinaranas.

No caso dos Gleissolos, foram descritos dois perfis nas Campinaranas, no entanto, sua ocorrência não é registrada para esta vegetação. Estes solos são comuns em áreas de influência fluvial e em comunidades vegetais denominadas 
TABELA 3: Número e porcentagem de perfis de solo estudados no Projeto RADAMBRASIL nas tipologias vegetais das Campinaranas e nos Contatos Campinaranas/Florestas.

TABLE 3: Number and percentage of soil profiles studied in the RADAMBRASIL Project on the vegetation types of "Campinaranas" and contact of "Campinaranas"/Forests.

\begin{tabular}{lccccccccc}
\hline \multirow{2}{*}{ Vegetação } & \multicolumn{7}{c}{ Número de perfis de solo estudados por classe de solo } \\
\cline { 2 - 10 } & E & R & G & S & L & F & P & C & TOTAL \\
\hline Campinaranas (Gl + $\mathrm{Ar}+\mathrm{Fl})$ & 19 & 8 & 2 & 1 & 1 & 1 & - & - & 32 \\
Gramíneo-Lenhosa (Gl) & 2 & 1 & - & - & - & - & - & - & 3 \\
Arborizada (Ar) & 7 & 2 & 1 & - & - & - & - & - & 10 \\
Florestada (Fl) & 10 & 5 & 1 & 1 & 1 & 1 & - & - & 19 \\
Contato Campinaranas/Florestas Aberta e & 5 & 6 & 5 & 2 & 3 & 2 & 10 & 2 & 35 \\
Densa & & & & & & &
\end{tabular}

\begin{tabular}{lrllllllll}
\hline TOTAL & 24 & 14 & 7 & 3 & 4 & 3 & 10 & 2 & 67 \\
\hline Em que: E - Espodossolos; $\mathrm{R}$ - Neossolos; $\mathrm{G}$ - Gleissolos; $\mathrm{S}$ - Planossolos; $\mathrm{L}$ - Latossolos; $\mathrm{F}$ - Plintossolos;
\end{tabular}
$\mathrm{P}$ - Argissolos; C - Cambissolos.

Formações Pioneiras, que variam desde pantanosas (herbáceas) até os agrupamentos de Palmae dos gêneros Euterpe e Mauritia, constituindo os açaizais e buritizais. No entanto, na Folha NA.20 Boa Vista (BRASIL, 1975a), as Campinaranas foram identificadas e descritas de maneira generalizada, com a distinção das Formações Pioneiras Arbóreas, Arbustivas e Lenhosa-Graminoides. Neste sentido, confundem-se as Campinaranas com as verdadeiras Formações Pioneiras de influência fluvial descritas por Veloso et al. (1991) e outros relatórios do Projeto RADAMBRASIL.

Nas áreas de contato Campinaranas/ Florestas ocorre uma maior diversificação de solos, com destaque para os Argissolos, com 10 perfis coletados (Tabela 3). Predominam, tipicamente, os solos mais argilosos, comparados com os solos das Campinaranas, mais arenosos. Com mais de 3 perfis coletados destacam-se também os Gleissolos, Latossolos, Neossolos e Espodossolos (Tabela 3), os quais corroboram com a diversidade pedológica do ambiente transicional.

\section{Os Solos das Campinaranas}

Os principais perfis de solos são os Espodossolos e os Neossolos, que correspondem a 27 dentre os 32 perfis de solos amostrados (Tabela 3). Em média, são solos ácidos $(\mathrm{pH}$ entre 4,1 a $5,4)$, de baixa fertilidade ( $\mathrm{SB}>1,2 \mathrm{cmol}_{\mathrm{c}} \mathrm{dm}^{-3}$ ) e distróficos (Tabela 4) e se destacam como solos muito arenosos, com média geral maior que 55 dag $\mathrm{kg}^{-1}$ de areia e menor que $10 \mathrm{dag}^{\mathrm{kg}}{ }^{-1}$ de argila. $\mathrm{O}$ desvio padrão elevado para as frações areia grossa e fina (Tabela 4), possivelmente, é associado às variações do material de origem, o qual varia desde sedimentos finos retrabalhados pelos ventos aos sedimentos mais grosseiros depositados por rios e lagos. De modo geral os valores médios de areia total nos solos das Campinaranas variam de 54,8 a 91,1 dag $\mathrm{kg}^{-1}$ e nos solos das áreas de contato Campinarana/Floresta de 41,9 a 74,5 dag $\mathrm{kg}^{-1}$. Os solos mais arenosos prevalecem nas Campinaranas e, de acordo com os dados, espera-se que sua ocorrência seja associada a valores mínimos de 55 dag $\mathrm{kg}^{-1}$ de areia, na média geral em cada perfil de solo.

As Campinaranas Florestadas e Arborizadas possuem solos com maiores teores de $\mathrm{MO}$ em superfície em associação direta com a CTC e a SB (Tabela 4). Os Espodossolos são mais ricos em superfície que os Neossolos e, normalmente, estão associados aos agrupamentos arbóreo-arbustivos, que incorporam mais biomassa vegetal ao solo. Estes solos apresentam horizontes superficiais e subsuperficiais ricos em carbono orgânico e prevalecem nas Campinaranas Florestadas (Tabela 4). Diferentemente, as fisionomias mais arbustivas apresentam-se em mosaicos, em unidades de mapeamento de Neossolos (Quartzarênicos) com associações de Espodossolos, a depender da escala de mapeamento.

Os Espodossolos apresentam aumento da Matéria Orgânica (MO) em subsuperfície (horizonte espódicos), associado ao aumento da CTC, de P assimilável e da Saturação por $\mathrm{Al}$ (m); o que sugere com formação dos complexos MO-Al, com elevada afinidade por fosfatos (NOVAIS et al., 2007). A matéria orgânica do solo, quando não é mineralizada ou retida nos horizontes subsuperficiais (espódicos), 
TABELA 4: Resultados da análise química e física, com média e desvio padrão (entre parênteses) das camadas dos principais solos coletados nas Campinaranas, sob as diferentes fitofisionomias.

TABLE 4: Results of the chemical and physical analysis, with average and standard deviation (among parenthesis) of the layers of the main soils collected in Campinaranas, under the different vegetation types.

\begin{tabular}{|c|c|c|c|c|c|c|c|c|c|c|c|}
\hline \multirow{2}{*}{ CAMADAS } & \multirow{2}{*}{$\mathrm{pH} \mathrm{H}_{2} \mathrm{O}$} & $\mathrm{P}$ & SB & $\mathrm{T}$ & $\mathrm{V}$ & $\mathrm{m}$ & MO & $\mathrm{AG}$ & $\mathrm{AF}$ & Silte & Argila \\
\hline & & $\mathrm{mg} \mathrm{dm} \mathrm{dm}^{-3}$ & $\mathrm{cmol}$ & $\mathrm{dm}^{-3}$ & \multicolumn{2}{|c|}{------ \% ----- } & \multicolumn{5}{|c|}{-------------- dag kg ${ }^{-1}$---------------- } \\
\hline \multicolumn{12}{|c|}{ Campinarana Florestada } \\
\hline \multicolumn{12}{|c|}{ Espodossolo (10 perfis) } \\
\hline Superficial & $4,1(0,4)$ & $0,8(0,8)$ & $0,5(0,2)$ & $13,1(10)$ & $7,4(7,5)$ & $49,7(33,4)$ & $8,1(8,3)$ & $38,3(21,0)$ & $37,4(17,0)$ & $19,3(11,9)$ & $5,0(4,0)$ \\
\hline Eluvial & $4,7(0,5)$ & $0,8(1,1)$ & $0,2(0,2)$ & $4,1(4,2)$ & $12,7(15,5)$ & $34,6(35,9)$ & $1,1(1,1)$ & $39,9(22,3)$ & $40,3(17,2)$ & $15,8(8,6)$ & $3,9(4,4)$ \\
\hline Subsuperficial & $4,8(0,7)$ & $4,1(9,4)$ & $0,3(0,2)$ & $7,4(4,7)$ & $6,7(11,6)$ & $69,4(28,3)$ & $2,5(1,7)$ & $39,6(14,3)$ & $35,9(11,6)$ & $16,7(8,6)$ & $7,8(3,9)$ \\
\hline \multicolumn{12}{|c|}{ Neossolo (5 perfis) } \\
\hline Superficial & $4,6(0,7)$ & $0,5(0,5)$ & $0,2(0,1)$ & $6,1(2,2)$ & $4,2(4,6)$ & $80,3(13,5)$ & $2,4(1,5)$ & $39,6(26,8)$ & $39,0(24,5)$ & $14,9(8,0)$ & $6,5(4,9)$ \\
\hline Eluvial & $4,6(0,8)$ & $0,5(0,6)$ & $0,1(0,1)$ & $4,9(1,5)$ & $3,3(2,6)$ & $85,0(8,8)$ & $1,8(0,6)$ & $26,9(15,7)$ & $46,8(14,3)$ & $16,6(9,5)$ & $9,7(3,9)$ \\
\hline Subsuperficial & $4,7(0,5)$ & $0,4(0,5)$ & $0,1(0,1)$ & $1,9(1,0)$ & $6,0(4,4)$ & $62,4(36,5)$ & $0,5(0,1)$ & $34,4(22,2)$ & $42,4(18,1)$ & $14,9(7,5)$ & $8,4(5,3)$ \\
\hline \multicolumn{12}{|c|}{ Campinarana Arborizada } \\
\hline \multicolumn{12}{|c|}{ Espodossolo (7 perfis) } \\
\hline Superficial & $4,4(0,7)$ & $2,0(1,9)$ & $1,2(1,9)$ & $28,7(35,6)$ & $3,6(1,2)$ & $63,1(27,0)$ & $12,9(12,6)$ & $35,4(30,3)$ & $37,1(31,6)$ & $24,1(30,1)$ & $3,5(1,4)$ \\
\hline Eluvial & $5,2(0,4)$ & $0,9(0,7)$ & $0,1(0,1)$ & $1,4(1,0)$ & $24,3(30,1)$ & $49,9(38,0)$ & $0,6(0,4)$ & $41,2(18,1)$ & $41,5(16,9)$ & $15,6(7,5)$ & $1,7(1,1)$ \\
\hline Subsuperficial & $4,7(0,5)$ & $2,5(4,1)$ & $0,1(0,1)$ & $7,0(3,9)$ & $1,9(1,6)$ & $90,8(9,5)$ & $2,1(1,1)$ & $40,6(20,6)$ & $41,7(16,2)$ & $13,7(8,3)$ & $4,0(2,9)$ \\
\hline \multicolumn{12}{|c|}{ Neossolo (2 perfis) } \\
\hline Superficial & $5,1(1,1)$ & $1,0(0,0)$ & $0,1(0,2)$ & $2,8(2,9)$ & $10,0(7,1)$ & $38,5(54,4)$ & $2,1(2,2)$ & $2,1(1,6)$ & $40,5(4,7)$ & $55,2(8,3)$ & $2,3(1,0)$ \\
\hline Eluvial & 5,4 & 1,0 & 0,0 & 0,6 & 18,0 & 0,0 & 0,4 & 7,0 & 56,0 & 37,0 & 0,0 \\
\hline$\underline{\text { Subsuperficial }}$ & $5,1(0,6)$ & $1,0(0,0)$ & $0,1(0,2)$ & $1,2(0,2)$ & $35,6(26,3)$ & $26,5(37,5)$ & $0,3(0,1)$ & $5,0(5,8)$ & $57,9(15,6)$ & $31,6(4,3)$ & $5,5(5,5)$ \\
\hline \multicolumn{12}{|c|}{ Campinarana Gramíneo-Lenhosa } \\
\hline \multicolumn{12}{|c|}{ Espodossolo (2 perfis) } \\
\hline Superficial & 5,3 & 1,0 & 0,1 & 0,6 & 16,0 & 81,0 & 0,7 & 50,0 & 47,0 & 1,0 & 2,0 \\
\hline Eluvial & $5,4(0,6)$ & $1,2(0,3)$ & $0,1(0,0)$ & $1,4(1,6)$ & $15,9(19,9)$ & $72,7(22,2)$ & $0,5(0,2)$ & $37,7(17,4)$ & $55,5(17,6)$ & $5,8(1,7)$ & $1,0(1,4)$ \\
\hline Subsuperficial & $4,7(0,8)$ & $23,1(29,8)$ & $0,0(0,0)$ & $12,7(12,2)$ & $0,9(0,2)$ & $95,6(3,4)$ & $3,8(4,0)$ & $42,0(15,6)$ & $44,0(28,3)$ & $9,5(10,6)$ & $4,5(2,1)$ \\
\hline \multicolumn{12}{|c|}{ Neossolo (1 perfil) } \\
\hline Eluvial & 5,2 & 1,2 & 0,0 & 1,7 & 1,2 & 95,3 & 1,8 & 23,0 & 57,0 & 19,0 & 1,0 \\
\hline Subsuperficial & 5,0 & 1,1 & 0,0 & 0,7 & 0,0 & 100,0 & 0,8 & 37,0 & 50,0 & 12,0 & 1,0 \\
\hline
\end{tabular}

pode ser lixiviada para os corpos d'água de superfície como os rios e lagos.

Os Neossolos são ainda mais pobres quimicamente que os Espodossolos e, normalmente, são solos alagados, na maior parte do ano e sofrem secas severas de poucos meses, ou até semanas, quando há o rebaixamento do nível do lençol freático. Sobre estes solos predomina uma fisionomia herbácea, altamente susceptível ao fogo durante os períodos de maior seca, o que pode estar relacionado com as grandes extensões campestres, que parecem ter coevoluído com todo esse ecossistema arenícola de plantas anãs, com adaptações morfológicas de folhas coriáceas, cutículas espessas, pilosidade, estômatos crípticos e lenho muito duro.

\section{Os Solos das Áreas Ecotonais do Contato Campinarana/Florestas}

Nas áreas de contato, ocorre maior variedade de solos argilosos, os quais não estão presentes nas áreas de solos arenosos dos ecossistemas das Campinaranas (Tabela 5). Estes solos são em média mais ácidos que os solos das Campinaranas, com pH entre 3,7 a 4,8, também de baixa fertilidade ( $\mathrm{SB}<1,5$ $\mathrm{cmol}_{\mathrm{c}} \mathrm{dm}^{-3}$ ) e distróficos (Tabela 5). Os Argissolos são dominantes nestas áreas, os quais possuem baixo gradiente textural e são pouco argilosos (Tabela 5). Os Neossolos e Espodossolos possuem características muito semelhantes com os solos amostrados nas Campinaranas. São solos arenosos (com areia total $>64 \mathrm{dag}^{-1}$ ), ácidos, distróficos e de baixa fertilidade (Tabela 5). Da mesma forma, possuem desvio padrão mais elevado para areia grossa e fina, o que sugere variações do material de origem. Ocorrem ainda alguns Latossolos com variações texturais, indicadas pelo desvio padrão mais alto na areia e argila (Tabela 5). O menor conteúdo de argila nos horizontes superficiais dos Gleissolos (Tabela 5), quando comparados com 
os subsuperficiais, possivelmente é associado aos processos de ferrólise e acidólise, comuns destes ambientes de solos alagados.

De maneira geral, mesmo com a maior diversificação pedológica, os solos selecionados guardam semelhanças com os solos encontrados nas Campinaranas, o que se relaciona com as características de transição sequencial de solos discutida por Mafra et al. (2002). Estes autores discutem a formação de solos na região do alto Rio Negro e destacam as transformações in situ de Latossolos em areias brancas hidromórficas e, posteriormente, a formação de Espodossolos hidromórficos, nos quais o principal processo pedogeoquímico envolvido na perda de argila seria a acidólise, provocando dissolução dos argilominerais presentes (gibbsita e caulinita). Os Espodossolos possuem o maior conteúdo médio de MO em superfície (Tabela 5), comparado às outras classes de solos estudados, nas quais, comumente, destacam-se turfeiras espessas sob horizontes A ricos em carbono orgânico (DUBROEUCQ e VOLKOFF, 1998).

\section{CONCLUSÕES}

A distribuição das unidades geológicas de sedimentos clásticos arenosos na Amazônia
Ocidental apresenta boa relação com a distribuição das Campinaranas, apesar da preponderância morfoclimática (precipitação pluvial alta) determinante em sua formação.

A partir da análise dos dados e da predominância absoluta dos solos arenosos nas Campinaranas, comparada aos solos das áreas ecotonais, sugere-se um limite mínimo de 55 dag $\mathrm{kg}^{-1}$ de areia nos solos para a ocorrência das Campinaranas Amazônicas. Os solos mais argilosos são reportados apenas para as áreas ecotonais Florestas-Campinaranas, marginais aos corpos arenosos.

Verifica-se predomínio absoluto dos Espodossolos e Neossolos Quartzarênicos nas Campinaranas. Mesmo em diferentes formações geológicas (granitos, gnaisses, arenitos) e com processos pedogenéticos distintos, estes solos possuem características morfológicas, químicas e físicas muito semelhantes.

Apesar da diversidade pedológica das áreas ecotonais, os solos encontrados guardam semelhanças com os solos das Campinaranas.

As Campinaranas são verdadeiros ecossistemas arenícolas de grande extensão na Amazônia brasileira, os quais estocam grandes quantidades de carbono orgânico nos horizontes subsuperficiais do solo, característicos dos

TABELA 5: Resultado da análise química e física, com média e desvio padrão (entre parênteses) dos principais solos coletados nas áreas de contato Campinaranas /Florestas.

TABLE 5: Result of the chemical and physical analysis, with average and standard deviation (among parenthesis) of the main soils collected in the contact areas Campinaranas / Forests.

\begin{tabular}{|c|c|c|c|c|c|c|c|c|c|c|c|}
\hline \multirow{2}{*}{ CAMADAS } & \multirow{2}{*}{$\mathrm{pH} \mathrm{H}_{2} \mathrm{O}$} & $P$ & SB & $\mathrm{T}$ & $\mathrm{V}$ & $\mathrm{m}$ & $\mathrm{MO}$ & $\mathrm{AG}$ & $\mathrm{AF}$ & Silte & Argila \\
\hline & & $\overline{m g ~ d m^{-3}}$ & ---- cmo & $1 \mathrm{dm}^{-3}---$ & \multicolumn{2}{|c|}{---------- \% ----------- } & \multicolumn{5}{|c|}{ 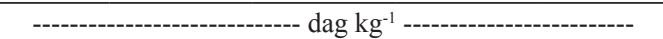 } \\
\hline \multicolumn{12}{|c|}{ Argissolo (10 perfis) } \\
\hline Superficial & $4,2(0,5)$ & 0,0 & $0,5(0,2)$ & $7,9(3,1)$ & $7,1(5,0)$ & $63,0(26,2)$ & $2,5(1,8)$ & $17,0(14,5$ & $31,1(15,1)$ & $29,4(10,6)$ & $22,6(10,7)$ \\
\hline Subsuperficial &, $7(2,0)$ & 0,0 & $4(0,3)$ & $3,9(2,9)$ & $10,6(6,4)$ & $52,7(30,4)$ & $0,6(0,5)$ & $22,7(30,2)$ & $27,1(15,3)$ & $19,9(13,9)$ & $28,6(8,6)$ \\
\hline \multicolumn{12}{|c|}{ Neossolos (6 perfis) } \\
\hline Superficial & $4,1(0,5)$ & $1,0(0,6)$ & $0,8(0,2)$ & $11,6(4,6)$ & $8,2(3,7)$ & $64,5(10,1)$ & $4,0(3,2)$ & $59,5(20,1)$ & $14,3(7,5)$ & $20,8(12,0)$ & $5,4(3,3)$ \\
\hline Eluvial & $4,6(0,7)$ & $0,6(0,6)$ & $0,4(0,3)$ & $4,0(1,4)$ & $11,5(12)$ & $68,0(32,5)$ & $1,1(0,6)$ & $44,0(2,8)$ & $20,5(3,5)$ & $27,0(2,8)$ & $8,5(3,5)$ \\
\hline Subsu & $8(0,4)$ & $0,6(0,5)$ & $0,3(0,3)$ & $2,3(1,7)$ & $11,2(5,0)$ & $52,7(31,4)$ & $0,9(0,9)$ & $53,1(20,3)$ & $25,4(21,6)$ & $16,3(10,8)$ & $5,2(5,1)$ \\
\hline \multicolumn{12}{|c|}{ Espodossolo (5 perfis) } \\
\hline Superf & $3,7(0,3)$ & $1,0(1,4)$ & $1,5(2,3)$ & $15,8(10,6)$ & $8,1(7,2)$ & $61,6(35,8)$ & $7,2(6,7)$ & $35,4(10,6)$ & $39,9(16,9)$ & $22,5(13,2)$ & $2,2(1,0)$ \\
\hline Eluvial & $3,9(1,1)$ & $0,5(0,7)$ & $0,3(0,1)$ & $2,5(2,2)$ & $14,3(12,4)$ & $53,1(33,8)$ & $0,8(0,7)$ & $29,5(19,6)$ & $40,5(14,7)$ & $20,2(13,4)$ & $3,1(3,9)$ \\
\hline Subsuperficial & $4,3(0,4)$ & $0,5(0,7)$ & $0,3(0,1)$ & $6,9(4,5)$ & $6,9(5,8)$ & $76,4(15,9)$ & $1,8(1,7)$ & $28,4(16,3)$ & $44,7(16,2)$ & $17,8(13,0)$ & $9,0(5,9)$ \\
\hline \multicolumn{12}{|c|}{ Gleissolo (5 perfis) } \\
\hline Superf & $4,5(0,6)$ & $0,7(0,4)$ & $0,4(0,4)$ & $10,6(7,1)$ & $4,4(3,7)$ & $74,2(17,9)$ & $4,9(3,2)$ & $21,3(27,9)$ & $20,5(11,1)$ & $37,8(24,4)$ & $20,4(26,0)$ \\
\hline Subsuperficial & $4,8(0,4)$ & $0,6(0,5)$ & $0,3(0,2)$ & $3,5(2,0)$ & $7,0(3,7)$ & $84,3(8,9)$ & $0,7(0,3)$ & $17,6(23,3)$ & $24,4(11,9)$ & $28,0(16,8)$ & $30,0(24,9)$ \\
\hline \multicolumn{12}{|c|}{ Latossolo (3 perfis) } \\
\hline & $2(0,6)$ & $0,1(0,1)$ & $0,5(0,2)$ & $5,9(2,1)$ & $7,5(6,8)$ & $43,3(39,4)$ & $2,2(0,4)$ & $35,9(28,5)$ & $17,3(19,4)$ & $14,6(3,8)$ & $32,3(25,1)$ \\
\hline Subsuperficial & $4,5(0,6)$ & 0,0 & $0,4(0,3)$ & $4,2(1,3)$ & $7,8(6,7)$ & $37,0(39,8)$ & $0,9(0,4)$ & $29,9(24,8)$ & $17,7(19,7)$ & $12,0(5,7)$ & $40,4(26,1)$ \\
\hline
\end{tabular}


Espodossolos.

\section{AGRADECIMENTOS}

Agradecimentos ao Programa de Áreas Protegidas da Amazônia (Programa ARPA), ao ICMBio (Roraima), a equipe do Parque Nacional do Viruá e ao CNPq pelo apoio e financiamento deste trabalho.

\section{REFERÊNCIAS BIBLIOGRÁFICAS}

ALONSO, J. A. Characteristic avifauna of whitesand forests in northern Peruvian Amazonia. 2002. (MSc thesis), Louisiana State University, Baton Rouge, LA.

ANDERSON, A. B. Aspectos florísticos e fitogeográficos de Campinas e Campinaranas, na Amazônia Central, 1978. Dissertação (Mestrado em Ciências Biológicas) - INPA-FU, Manaus.

ANDERSON, A. B. White-sand Vegetation of Brazilian Amazonia. Biotropica, Flórida, v. 13, n. 3, p. 199-210, 1981.

ANDERSON, A. B.; PRANCE, G.T.; ALBUQUERQUE, B.W.P. Estudos sobre as vegetações de Campinas Amazônica III: A vegetação lenhosa da Campina da Reserva Biológica INPA -SUFRAMA (Manaus-Caracaraí, km 62). Acta Amazonica, v. 5, n. 3, p. 225-246, 1975.

ANDRADE, $\mathrm{H}$. et al. Pedogeomorfologia e micropedologia de uma seqüência de Latossolo - Areia Quartzosa Hidromórfica sobre rochas cristalinas do Estado do Amazonas. Genomos. Belo Horizonte, v. 5, n. 1, p. 55-66. 1997.

ANDRADE, H. Evolução de uma seqüência de solos argilosos até arenosos no Complexo Guianense da Amazônia. 1990. 179 p. Tese (Doutorado), Escola Superior de Agricultura "Luiz de Queiroz", Piracicaba.

BRASIL. Ministério das Minas e Energia. Projeto RADAMBRASIL. Folha NA. 20 Boa Vista e parte das Folhas NA -21 Tumuqumaque, NB 20 Roraima e NB - 21, Rio de Janeiro, v. 8, 428 p. 1975a. (Levantamento dos Recursos Naturais, 8). BRASIL. Ministério das Minas e Energia. Projeto RADAMBRASIL. Folha NA. 21 Tumucumaque e parte da Folha NB. 21; geologia, geomorfologia, pedologia, vegetação e uso potencial da terra, Rio de Janeiro, 370 p. 1975b (Levantamento dos Recursos Naturais, 9).

BRASIL. Ministério das Minas e Energia. Projeto RADAMBRASIL. Folha NA. 19 Pico da Neblina; geologia, geomorfologia, pedologia, vegetação e uso potencial da terra. Rio de Janeiro, 380 p. 1976 (Levantamento dos Recursos Naturais, 11).

BRASIL. Ministério das Minas e Energia. Projeto RADAMBRASIL. Folhas SB/SC. 18 Javari/ Contamana; geologia, geomorfologia, pedologia, vegetação e uso potencial da terra, Rio de Janeiro, 420 p. 1977a (Levantamento de Recursos Naturais, 13).

BRASIL. Ministério das Minas e Energia. Projeto RADAMBRASIL. Folha SA. 19 Içá; geologia, geomorfologia, pedologia, vegetação e uso potencial da terra. Rio de Janeiro, 452 p. 1977b (Levantamento dos Recursos Naturais, 14).

BRASIL. Ministério das Minas e Energia. Projeto RADAMBRASIL. Folha SA. 20 Manaus; geologia, geomorfologia, pedologia, vegetação e uso potencial da terra. Rio de Janeiro, 628 p. 1978 (Levantamento dos Recursos Naturais, 18)

BRAVARD, S.; RIGHI, D. Podzols in Amazonia. Catena, n. 17, p. 461-475, 1990.

BRINKMAN, R. Ferrolysis, a hydromorphic soil forming process. Geoderma, Amsterdam, n. 3, p. 199-206, 1970.

CPRM, Companhia de Pesquisa de Recursos Minerais. Programa Levantamentos Geológicos Básicos do Brasil. Projeto de Mapeamento Geológico / Metalogenético Sistemático, Caracaraí: Folhas NA.20-Z-B e NA.20-Z-D inteiras e parte das folhas NA.20-Z-A, NA.20-Z-C, NA.21Y-C e NA.21-Y-A. Brasília, 2000.

DUBROEUCQ, D.; BLANCANEAUX, P. Les podzols du haut rio Negro, region de Marao, Venezuela. Environnement et relations lithologiques. In: RIGHI, D.; CHAUVEL, A., eds. Podzols et podzolisation. Paris, INRA, 1987. p. 37-52.

DUBROEUCQ, D.; VOLKOFF, B. From Oxisols to Spodosols and Histosols: evolution of the soil mantles in the rio Negro basin (Amazonia). Catena, n. 32, p. 245-280, 1998.

DUCKE, A.; BLACK, G.A. Notas sobre a fitogeografia da Amazônia brasileira. Boletim Técnico do Instituto Agronômico do Norte, Belém, n. 29, p. 1-62, 1954.

DUIVENVOORDEN, J. F. Patterns of tree species richness in rainforests of the middle Caqueta area, Colombia, NW Amazonia. Biotropica, Flórida, v. 28, n. 2, p. 142-158. 1996.

FERREIRA, C. A. C. Variação Florística e Fisionômica da Vegetação de Transição Campina, Campinara e Floresta de Terra Firme. 
1997, 112p. Dissertação (Mestrado em Ciências Biológica) UFRPE, Recife.

IBGE, Instituto Brasileiro de Geografia e Estatística. Manual Técnico da Vegetação Brasileira. Série Manuais Técnicos em Geociências, $n^{0} 1$, Rio de Janeiro, 1992. 92p.

IBGE, Instituto Brasileiro de Geografia e Estatística. Diretoria de Geociências. Coordenação de Recursos Naturais e Estudos Ambientais. Projeto Sistematização das Informações Sobre Recursos Naturais. 2000.

INMET. Instituto Nacional de Meteorologia. Disponível em: <(http://www.inmet.gov.br/html/ clima.php)> Acesso em: 20 de maio de 2008.

JARVIS, A. et al. Hole-filled seamless SRTM data v. 3, International Centre for Tropical Agriculture (CIAT). 2006. Disponível em http://srtm.csi.cgiar. org

LUCAS Y. et al. Transição Latossolos-podzóis sobre a formação Barreiras na região de Manaus, Amazônia. Revista Brasileira de Ciência do Solo, v. 8, p. 325-335, 1984.

MAFRA, A.L. et al. Pedogênese numa seqüência Latossolo-Espodossolo na região do alto rio Negro, Amazonas. Revista Brasileira de Ciência do Solo, v. 26, p.381-394, 2002.

NOVAIS, R. F.; SMYTH, T. J.; NUNES, F. N. Fósforo. SBCS, Viçosa, 2007. Fertilidade do Solo, 1017p. (eds. NOVAIS, R.F. et al.).

OLIVEIRA, A. A. de; DALY, D. C. Florestas do

Rio Negro. São Paulo. Companhia das Letras: UNIP, 2001.

PEEL, M. C.; FINLAYSON, B. L.; McMAHON,

T. A. Updated world map of the Köppen-Geiger climate classification. Hydrol. Earth Syst. Sci., v. 11, p. 1633-1644, 2007.
POLETO, F.; ALEIXO, A. Implicações biogeográficas de novos registros ornitológicos em um enclave de vegetação de campina no sudoeste da Amazônia brasileira. Revista Brasileira de Zoologia. v. 22, p. 1196-1200, 2005.

PRANCE, G.T. Islands in Amazonia. Phil. Trans. R. Soc. London v. 351, n. 1341, p. 823-33, 1996.

PRANCE, G.T.; SCHUBART, H.O.R. Nota preliminar sobre a origem das campinas abertas de areia branca do rio Negro. Acta Amazonica. v. 3, n. 4, p. 567-550, 1978.

SANTOS, J.O.S.; NELSON, B.W. Os campos de dunas do Pantanal Setentrional. In: CONGRESSO LATINO-AMERICANO, 8, Caracas, Venezuela, Anais...1995. 9p.

SCHAEFER, C. E. G. R.; DALRYMPLE, J. Landscape Evolution In Roraima, North Amazonia: Planation, Paleosols And Paleoclimates. Zeitschrift für Geomorphologie, Berlin, v. 39, n. 1, p. 1-28, 1995.

SCHAEFER C. E. G. R. et al. Soil and vegetation carbon stocks in Brazilian Western Amazonia: relationships and ecological implications for natural landscapes. Environmental Monitoring and Assessment, p. 1-15, 2007.

SILVEIRA, M. Vegetação e Flora das Campinaranas do Sudoeste Amazônico. S.O.S. Amazônia. Rio Branco, 2003. 26p.

SOMBROEK, W.G. Amazon Soils: a Reconnaissance of the Soils of the Brazilian Amazon Valley. Pudoc, Wageningen, 1966. $292 \mathrm{p}$.

VELOSO, H.P.; RANGEL FILHO, A.L.R.; LIMA, J.C.A. Classificação da Vegetação Brasileira, adaptada a um Sistema Universal. Rio de Janeiro. IBGE, 1991. 